Check for updates

Cite this: Phys. Chem. Chem. Phys., $2018,20,20732$

DOI: $10.1039 / \mathrm{c} 8 \mathrm{cp} 91812 \mathrm{k}$

rsc.li/pccp

\section{Correction: Improved fill factor in inverted planar perovskite solar cells with zirconium acetate as the hole-and-ion-blocking layer}

\author{
Xuewen Zhang, Chunjun Liang, * Mengjie Sun, Huimin Zhang, Chao Ji, Zebang Guo, \\ Yajun Xu, Fulin Sun, Qi Song and Zhiqun He*
}

Correction for 'Improved fill factor in inverted planar perovskite solar cells with zirconium acetate as the hole-and-ion-blocking layer' by Xuewen Zhang et al., Phys. Chem. Chem. Phys., 2018, 20, 7395-7400.

The authors would like to correct the name of the chemical material investigated in the work from zirconium acetate to zirconium(Iv) acetylacetone, which results in the following changes:

(1) The title of the article should be corrected as "Improved fill factor in inverted planar perovskite solar cells with zirconium(rv) acetylacetone as the hole-and-ion-blocking layer".

(2) In the abstract, the sentence "In this work, we used a new buffer layer, zirconium acetate $\left(\mathrm{Zr}(\mathrm{Ac})_{4}\right)$." should be amended to "In this work, we used a new buffer layer, zirconium(Iv) acetylacetone $\left(\mathrm{Zr}(\mathrm{Acac})_{4}\right)$."

(3) $\operatorname{Zr}(\mathrm{Ac})_{4}$ should be changed to $\operatorname{Zr}(\mathrm{Acac})_{4}$ throughout the article.

(4) Fig. 1 should be replaced with the amended figure below showing the correct chemical structure of zirconium(Iv) acetylacetone.
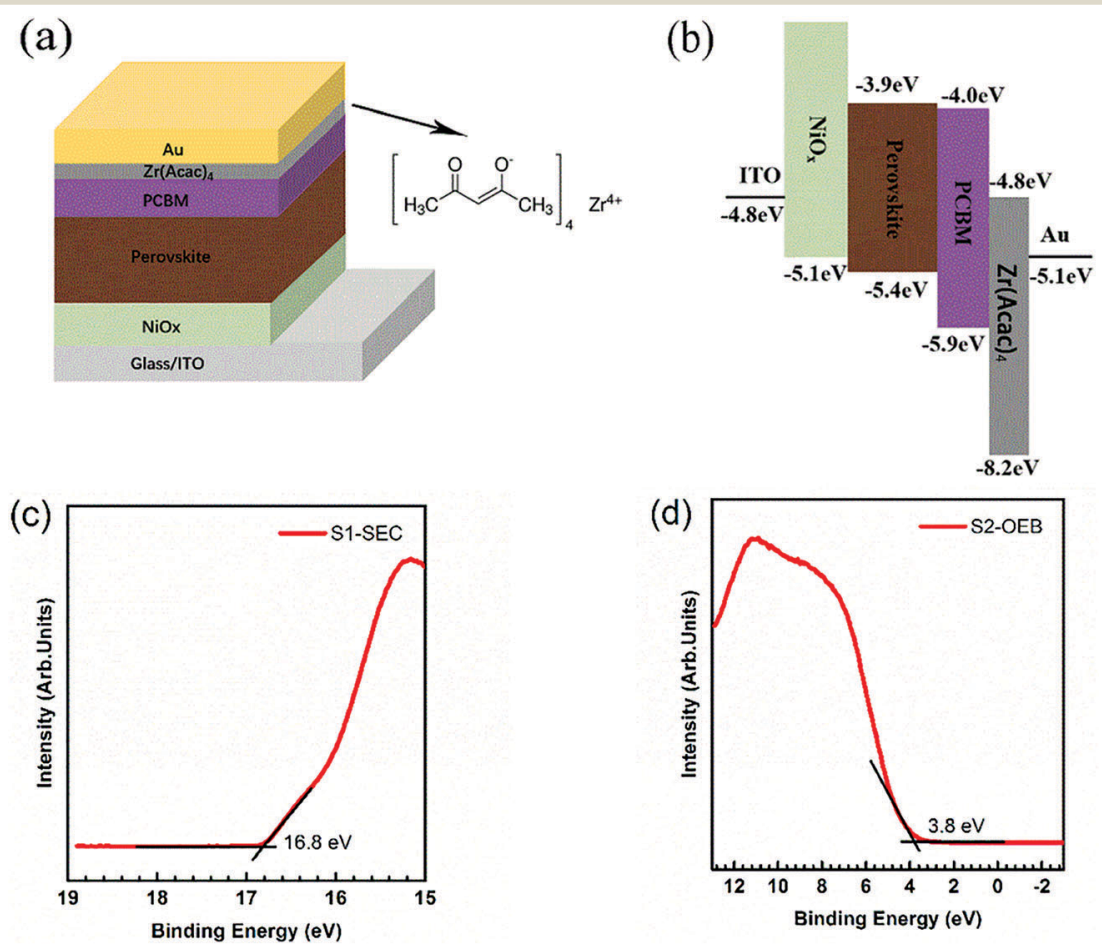

Fig. 1 (a) The architecture of $p-i-n$ perovskite solar cell with Zr(Acac) ${ }_{4}$ layer. (b) Energy diagram of the device. UPS spectra of Zr(Acac) 4 at the secondary electron cutoff ( $\left.E_{\text {cutoff }}\right)$ edge (c) and at the onset energy boundary (d).

The Royal Society of Chemistry apologises for these errors and any consequent inconvenience to authors and readers. 